\title{
TO ASSESS THE MAGNITUDE OF OXIDATIVE STRESS AND ANTIOXIDANT DEFENSE IN PREECLAMPSIA
}

\author{
Richa Pramod Priyamvada1, Rajkumar P. Patange2, Sanjay Kumar Patil ${ }^{3}$, Yamini S. Patil ${ }^{4}$
}

${ }_{1}^{1}$ Resident Department of Obstetrics and Gynaecology, Krishna Institute of Medical Sciences Deemed University, Karad. 2 Professor and HOD, Department of Obstetrics and Gynaecology, Krishna Institute of Medical Sciences Deemed University, Karad. ${ }^{3}$ Professor, Department of Obstetrics and Gynaecology, Krishna Institute of Medical Sciences Deemed University, Karad. ${ }^{4}$ Associate Professor, Department of Obstetrics and Gynaecology, Krishna Institute of Medical Sciences Deemed University, Karad.

\section{ABSTRACT}

Preeclampsia is a multifactorial disease. Recent studies show that free radical induced endothelial injury may be a factor in pathogenesis of preeclampsia and that a biochemical imbalance occurs with an increase of oxidative stress, lipoperoxidation and deficient antioxidants.

\section{AIMS AND OBJECTIVES}

To evaluate parameters of oxidative stress and antioxidant defense in preeclampsia and thereby find any aetiological correlation.

\section{MATERIALS AND METHODS}

Study was carried on pregnant and non-pregnant women placed in four groups. This study was done to assess Malondialdehyde (MDA), as marker of oxidative stress and Total Antioxidant Capacity (TAC) measured by Ferric Reducing Ability of Plasma (FRAP) in normal pregnancy and preeclampsia and comparing with non-pregnant females.

\section{RESULTS}

Study shows rise in MDA level highest in severe preeclampsia (192.8) followed by mild preeclampsia (151.8) than in normal pregnancy (105.9), and non-pregnant (95.8) showing significant increase in levels of MDA ( $\mathrm{p}<0.0001)$ in preeclamptic patients. TAC measured by FRAP significantly highest in severe preeclampsia (1725.6) followed by mild preeclampsia (1507) than in normal pregnancy (1203.3) and although there was increase in TAC in normal pregnant compared to non-pregnant (1173.7), increase was statistically insignificant.

\section{CONCLUSION}

Preeclampsia shows markedly increased oxidative stress as evidenced by significantly increased levels of malondialdehyde. There was strong correlation between total antioxidant capacity with severity of preeclampsia.

\section{KEYWORDS}

Malondialdehyde, Ferric Reducing Ability of Plasma, Preeclampsia, Total Antioxidant Capacity.

HOW TO CITE THIS ARTICLE: Priyamvada RP, Patange RP, Patil SK, et al. To assess the magnitude of oxidative stress and antioxidant defense in preeclampsia. J. Evolution Med. Dent. Sci. 2016;5(57):3898-3902, DOI: 10.14260/jemds/2016/893

\section{INTRODUCTION}

Pregnancy is a physiological stress in which many changes occur in the milieu interior of the body, more stress is being laid on the biochemical changes, which occur in the blood during the normal pregnancy and becomes exaggerated in complications of pregnancy like pre-eclampsia. ${ }^{1}$

Oxidative stress increases during preeclampsia and results in increased production of lipid peroxides, reactive oxygen species and superoxide anion radicals to cause endothelial injury and dysfunction, platelet and neutrophil activation. 2,3

Recent evidences have shown that there is a biochemical imbalance in preeclampsia with an increase of oxidative stress and lipoperoxidation and at the same time a deficient antioxidant protection. ${ }^{4}$

Lipid peroxidation may play a role in the aetiology of the disease. ${ }^{2,5,6,7}$

Financial or Other, Competing Interest: None.

Submission 02-04-2016, Peer Review 26-05-2016,

Acceptance 02-06-2016, Published 15-07-2016.

Corresponding Author:

Dr. Richa Pramod Priyamvada,

Room No. 301, IHR Hostel,

Krishna Institute of Medical Sciences Deemed University,

Karad.

E-mail: richa.priyamvada@gmail.com

DOI: $10.14260 /$ jemds $/ 2016 / 893$
Benzie and his research group in 1996 for the first time described a method to measure the total antioxidant capacity known as the ferric reducing ability of plasma. ${ }^{8}$

The present study has been undertaken to determine the changes in serum levels of peroxidation product, i.e. Malondialdehyde (MDA) and total antioxidant capacity measured by FRAP assay.

\section{AIMS AND OBJECTIVES}

To evaluate the parameters of oxidative stress and antioxidant defence in preeclampsia and thereby find any aetiological correlation.

\section{MATERIALS AND METHODS}

Study was carried out over a period of 2 years from June 2013 to June 2015, on pregnant and non-pregnant women attending OPD or admitted in Obstetrics and Gynaecology Department of Krishna Hospital, Karad. Women were placed in following four groups

- Group A: Non-pregnant normotensive $(n=62)$

- Group B: Pregnant women without preeclampsia between 28 to 40 weeks gestation $(n=62)$.

- Group C: Antenatal subjects with mild preeclampsia between 28 to 40 weeks gestation $(n=63)$. 
- Group D: Antenatal subjects with severe preeclampsia between 28 to 40 weeks gestation $(n=63)$.

\section{Design of Study}

Prospective experimental study.

\section{Sample Size}

Using following formula and data from previous literature, the sample size calculated was minimum 53 in each group. We took 250 as our total sample size.

$$
\mathrm{N}=\frac{\mathrm{Z}^{2} * \mathrm{SD}^{2}}{\text { Mean }{ }^{*} \mathrm{E}^{2}}
$$

\section{Exclusion Criteria}

Patients with

- Chronic hypertension.

- Hepatitis.

- Renal disease.

- Thyroid disease.

- Collagen vascular disease.

- Haemoglobin $\leq 8 \mathrm{gm} \%$.

- $\quad$ Patient treated with PCOS.

\section{Inclusion Criteria}

- $\quad$ Age 19-29 years.

- Primigravida females.

Single Sample was taken and each Serum Sample from different Groups was Evaluated for

Malondialdehyde [MDA]

A product of lipid peroxidation process as a marker for oxidative stress. ${ }^{6}$

- $\quad$ Reagent 1- Trichloroacetic acid 17.5\%.

- $\quad$ Reagent 2-Trichloroacetic acid 70\%.

- $\quad$ Reagent 3-Thiobarbituric acid $0.6 \%$.

The reaction was performed in Pyrex test tube labelled as: Test and Blank into which the following reagents were pipette as follows:

\begin{tabular}{|c|c|c|}
\hline Reagent & Test & Blank \\
\hline Serum & $1 \mathrm{~mL}$ & --- \\
\hline Distilled water & --- & $1 \mathrm{~mL}$ \\
\hline Reagent 1 & $1 \mathrm{~mL}$ & $1 \mathrm{~mL}$ \\
\hline
\end{tabular}

\begin{tabular}{|c|c|c|}
\hline Reagent 2 & $1 \mathrm{~mL}$ & $1 \mathrm{~mL}$ \\
\hline Reagent 3 & $1 \mathrm{~mL}$ & $1 \mathrm{~mL}$ \\
\hline \multicolumn{2}{|c|}{ Table 1: MDA Reaction } \\
\hline
\end{tabular}

- The tubes were mixed well and incubated in boiling bath for $15 \mathrm{~min}$, allowed to cool, then the tubes were left to stand at room temp for $20 \mathrm{~min}$.

- Then the tubes were centrifuged at $2000 \mathrm{rpm}$ for $15 \mathrm{~min}$ and then the supernatant layer was read at $534 \mathrm{~nm}$.

- Calculation

MDA (micromol/ml) = Abs (test) - Abs (blank) X 1000 .

\section{FRAP Assay}

It is a simple automated test measuring the ferric reducing ability of plasma. The ferric to ferrous ion reduction at low $\mathrm{pH}$ causes a coloured ferrous tripyridyltriazine complex to form. It has an intensive blue colour and can be monitored at 593 nm. ${ }^{8}$

FRAP method is a sensitive measurement of total antioxidant power.

Four tubes were taken and labelled as Test, Control, Standard and Blank.

\begin{tabular}{|c|c|c|c|c|}
\hline Reagent & $\begin{array}{l}\text { Test } \\
(\mu L)\end{array}$ & $\begin{array}{c}\text { Control } \\
(\mu \mathrm{L})\end{array}$ & $\begin{array}{c}\text { Standard } \\
(\mu \mathrm{L})\end{array}$ & $\begin{array}{c}\text { Blank } \\
(\mu \mathrm{L})\end{array}$ \\
\hline Acetate Buffer & 500 & 550 & 500 & 500 \\
\hline $\mathrm{FeCl}_{3}$ & 50 & -- & 50 & 50 \\
\hline TPTZ & 50 & 50 & 50 & 50 \\
\hline Sample & 80 & 80 & -- & -- \\
\hline Standard $\left(\mathrm{FeSO}_{4}\right)$ & -- & -- & 80 & -- \\
\hline Distilled water & -- & -- & -- & 80 \\
\hline \multicolumn{5}{|c|}{ Table 2: FRAP Reaction } \\
\hline
\end{tabular}

The tubes were incubated at $37^{\circ} \mathrm{C}$ for $30 \mathrm{~min}$ and read at $593 \mathrm{~nm}$ in spectrophotometer.

Calculation

FRAP (micromole $/ \mathrm{L})=$ Abs (test) - Abs (control) $X 1000$ Abs (std) - Abs (blank)

\section{Statistical Analysis}

Parametric data are expressed as mean and Standard Deviation (SD) and analysed using the ANOVA (analysis of variance) test, Tukey Kramer multiple comparisons test and Pearson's correlation coefficient test (GraphPad InStat 3.06 software).

P-value $<0.05$ was considered as statistically significant.

\section{RESULTS}

\begin{tabular}{|c|c|c|c|c|c|c|}
\hline $\begin{array}{c}\text { MDA } \\
\text { (Micromole/mL) }\end{array}$ & Group A & Group B & Group C & Group D & P value & F value \\
\hline Mean+SD & $95.86+5.46$ & $105.96+5.38$ & $151.88+9.9$ & $192.81+3.3$ & $<0.0001$ & 2967.1 \\
\hline \multicolumn{7}{|c|}{ Table 3: Comparison of MDA Value in all Four Groups } \\
\hline
\end{tabular}




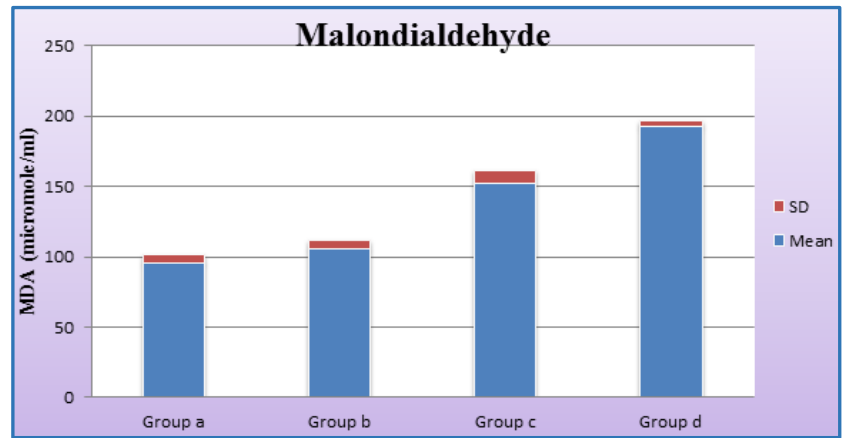

Graph 1: Comparison of MDA

From the above Table 3 and Graph 1, we conclude that mean serum Malondialdehyde level is highest in the severe preeclampsia group followed by mild preeclampsia more than normal pregnancy and least in non-pregnant females.

\begin{tabular}{|c|c|}
\hline Comparison & P value \\
\hline Non-pregnant vs Normal pregnant & $\mathrm{p}<0.001$ \\
\hline Non-pregnant vs Mild preeclampsia & $\mathrm{p}<0.001$ \\
\hline Non-pregnant vs Severe preeclampsia & $\mathrm{p}<0.001$ \\
\hline Normal pregnant vs Mild preeclampsia & $\mathrm{p}<0.001$ \\
\hline Normal pregnant vs Severe preeclampsia & $\mathrm{p}<0.001$ \\
\hline Mild preeclampsia vs Severe preeclampsia & $\mathrm{p}<0.001$ \\
\hline \multicolumn{2}{|c|}{ Table 4: Tukey-Kramer Multiple } \\
Comparison Test for MDA Value \\
\hline
\end{tabular}

As shown in Table 4, the p value when all four groups were compared with each other was $<0.001$, which is very significant suggesting that there was a significant difference in malondialdehyde levels among all four groups.

\begin{tabular}{|c|c|c|c|c|c|c|}
\hline FRAP (Micromole/mL) & Group A & Group B & Group C & Group D & P value & F value \\
\hline Mean+SD & $1173.71+71.42$ & $1203.35+58.9$ & $1507.06+69.8$ & $1725.6+55.6$ & $<0.0001$ & 1045.4 \\
\hline \multicolumn{7}{|c|}{ Table 5: Comparison of FRAP Value in All Four Groups } \\
\hline
\end{tabular}

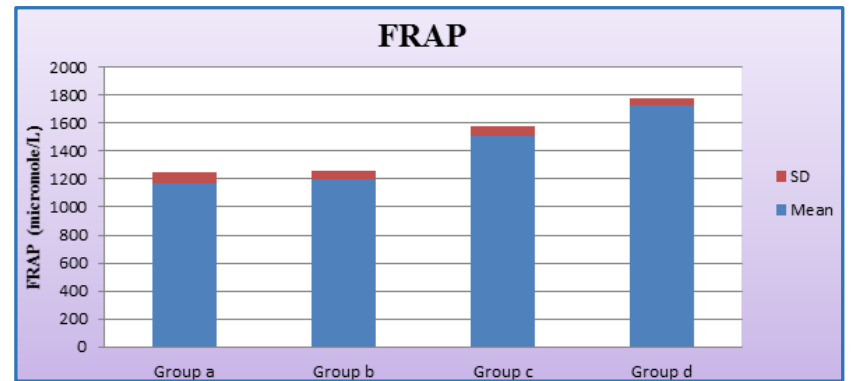

Graph 2: Comparison of FRAP

From the above Table 5 and Graph 2, we can conclude that the mean FRAP level is highest in the severe preeclampsia group followed by mild preeclampsia more than normal pregnancy and least in non-pregnant females.

\begin{tabular}{|c|c|}
\hline Comparison & P value \\
\hline Non-pregnant vs Normal pregnant & $\begin{array}{c}\mathrm{P}>0.05 \text { (not } \\
\text { significant) }\end{array}$ \\
\hline $\begin{array}{c}\text { Non-pregnant vs Mild } \\
\text { preeclampsia }\end{array}$ & $\mathrm{P}<0.001$ \\
\hline $\begin{array}{c}\text { Non-pregnant vs Severe } \\
\text { preeclampsia }\end{array}$ & $\mathrm{P}<0.001$ \\
\hline $\begin{array}{c}\text { Normal Pregnant vs Mild } \\
\text { preeclampsia }\end{array}$ & $\mathrm{P}<0.001$ \\
\hline $\begin{array}{c}\text { Normal Pregnant vs Severe } \\
\text { preeclampsia }\end{array}$ & $\mathrm{P}<0.001$ \\
\hline $\begin{array}{c}\text { Mild preeclampsia vs Severe } \\
\text { preeclampsia }\end{array}$ & $\begin{array}{c}\text { Table 6: Tukey-Kramer Multiple } \\
\text { Comparison Test for FRAP Value }\end{array}$ \\
\hline \multicolumn{2}{|c|}{}
\end{tabular}

As shown in Table 6, the $\mathrm{P}$ value in comparison between non-pregnant and normal pregnancy groups is $>0.05$, which is not significant suggesting that there is not much difference in FRAP levels between non-pregnant and normal pregnant females. Also the P value between comparison among all other groups is $<0.001$, which is very significant suggesting that there is significant difference in FRAP levels among all other groups.

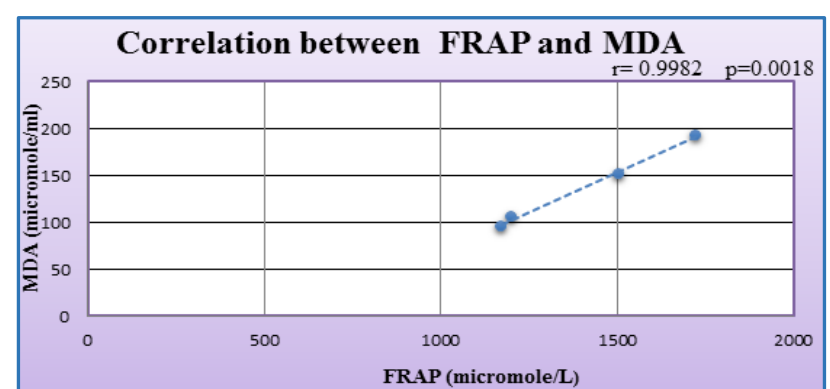

Graph 3: Correlation between FRAP and MDA

\begin{tabular}{|c|c|c|}
\hline Variable Correlation & r & p \\
\hline Correlation between FRAP and MDA & 0.9982 & 0.0018 \\
\hline \multicolumn{2}{|c|}{ Table 7: Correlation between FRAP and MDA } \\
\hline
\end{tabular}

As shown in Table 7 and Graph 3, there was significant correlation between FRAP and MDA (P 0.0018). Correlation value of 0.9982 indicated that there was a very strong positive correlation suggesting that as the FRAP levels increases malondialdehyde levels also increases.

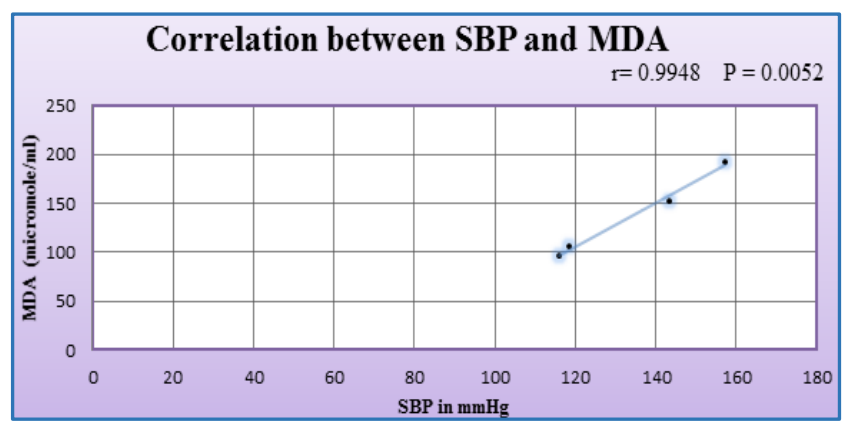

Graph 4: Correlation between SBP and MDA

\begin{tabular}{|c|c|c|}
\hline Variable Correlation & $\mathbf{r}$ & $\mathbf{p}$ \\
\hline Correlation between SBP and MDA & 0.9948 & 0.0052 \\
\hline \multicolumn{2}{|c|}{ Table 8: Correlation between SBP and $\mathbf{M D A}$} \\
\hline
\end{tabular}

As shown in Graph 4 and Table 8, there was significant correlation between SBP and MDA ( $\mathrm{p}=0.0052)$. Correlation value of 0.9948 indicated that there was a very strong positive correlation, which shows that as the SBP increases MDA levels 
also increases among all four groups suggesting that there is a significant correlation between MDA levels and severity of preeclampsia.

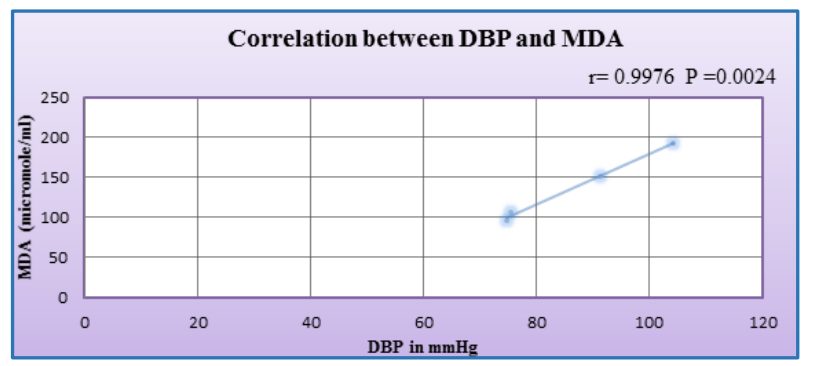

Graph 5: Correlation between DBP and MDA

\begin{tabular}{|c|c|c|}
\hline Variable Correlation & r & p \\
\hline Correlation between DBP and MDA & 0.9976 & 0.0024 \\
\hline \multicolumn{3}{|c|}{ Table 9: Correlation between DBP and MDA } \\
\hline
\end{tabular}

As shown in Graph 5 and Table 9, there was significant correlation between DBP and MDA ( $\mathrm{p}=0.0024)$. Correlation value of 0.9976 indicated that there was a very strong positive correlation, which shows that as the diastolic blood pressure increases MDA levels also increases among all four groups suggesting that there is a significant correlation between MDA levels and severity of preeclampsia.

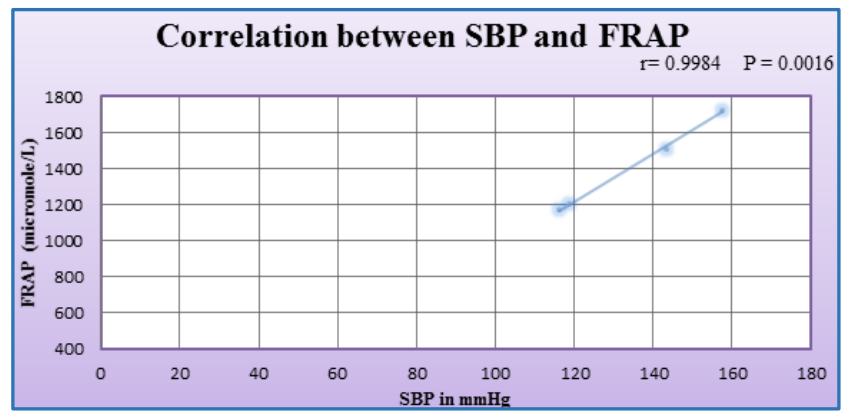

Graph 6: Correlation between SBP and FRAP

\begin{tabular}{|c|c|c|}
\hline Variable Correlation & r & p \\
\hline Correlation between SBP and FRAP & 0.9984 & 0.0016 \\
\hline \multicolumn{2}{|c|}{ Table 10: Correlation between SBP and FRAP } \\
\hline
\end{tabular}

As shown in Graph 6 and Table 10, there was significant correlation between SBP and FRAP (P 0.0016). Correlation value of 0.9984 indicated that there was a very strong positive correlation, which shows that as the SBP increases FRAP levels also increases suggesting that there is a significant correlation between TAC measured by FRAP assay and severity of preeclampsia.

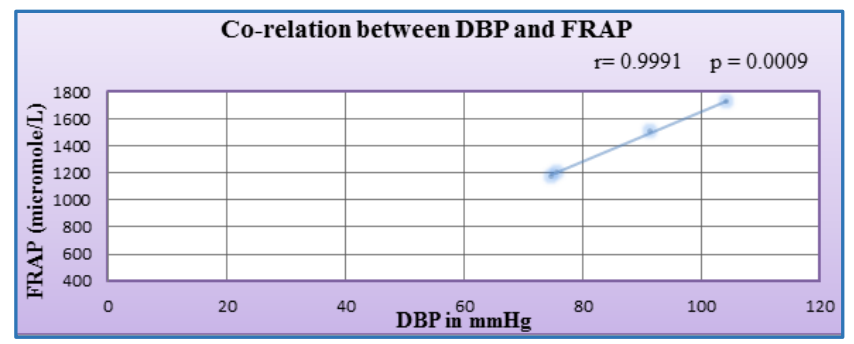

Graph 7: Correlation between DBP and FRAP

\begin{tabular}{|c|c|c|}
\hline Variable Correlation & r & p \\
\hline Correlation between DBP and FRAP & 0.9991 & 0.0009 \\
\hline \multicolumn{2}{|c|}{ Table 11: Correlation between DBP and FRAP } \\
\hline
\end{tabular}

As shown in Graph 7 and Table 11, there was significant correlation between DBP and FRAP (P 0.0009). Correlation value of 0.9991 indicated that there was a very strong positive correlation, which shows that as the diastolic blood pressure increases FRAP levels also increases among all four groups suggesting that there is a significant correlation between TAC measured by FRAP assay and severity of preeclampsia.

\section{DISCUSSION}

Recent investigations suggest that endothelial cell injury may be the initiator of pathophysiological events of preeclampsia.

Uncontrolled peroxidation of fatty acids and cholesterol alter membrane fluidity and permeability as lipid peroxides are toxic compounds that damage endothelial cells, increase peripheral vasoconstriction and increase thromboxane synthesis and decrease prostacyclin synthesis. 9,10

Malondialdehyde (A Lipid peroxidation product)

The increase in MDA shows the excessive ongoing lipid peroxidation in preeclampsia. This result is similar to many studies like study by Gohil J. T. et al, Jyoti Dave et al and Sadanand Patil et al.11,12,13

Correlation of MDA was studied with systolic and diastolic blood pressure and a significant positive correlation between MDA and systolic ( $\mathrm{r}=0.9950, \mathrm{p}$ value 0.0050$)$ and diastolic ( $\mathrm{r}$ 0.9916, p value 0.0084) blood pressure was observed. A significant positive correlation was also found by Shikha Saxena et al between serum MDA level and systolic $(\mathrm{r}=0.567$, $\mathrm{p}<0.001)$ and diastolic $(\mathrm{r}=0.443, \mathrm{p}<0.001)$ blood pressure. ${ }^{5}$

In contrast to our finding, Sahu et al noted a negative correlation of diastolic blood pressure with MDA ( $p>0.05) .{ }^{14}$

In a study by Chamy et al, they confirmed that during normal pregnancy lipid peroxidation is increased when compared with healthy non-pregnant females. As total antioxidant capacity (Enzymatic and non-enzymatic) also increased, a compensatory balance of the injury/defence ratio is maintained. Therefore, oxidative equilibrium may persist throughout pregnancy.

Preeclamptic women fail to develop this compensatory mechanism, which was confirmed in their study by increased MDA levels revealing an increase in lipidic membrane damage in preeclamptic patients as compared with healthy pregnant patients. This damage is more evident in severe preeclampsia group compared to mild preeclampsia group showing a close relation between degree of lipidic damage and clinical severity of preeclampsia. ${ }^{4}$

\section{Total Antioxidant Capacity}

FRAP assay measures mainly the antioxidant capacity of water soluble antioxidants (Uric acid, vit C, bilirubin) and to a lesser extent that of hydrophobic components (vit E) and sulfhydryl group of proteins.

The high contribution of uric acid as an antioxidant in preeclampsia patients is the reason which explains raised total antioxidant capacity in preeclampsia.

In total antioxidant capacity measured by FRAP method uric acid contributes to $60 \%$, Vit C $15 \%$, thiol protein $10 \%$, tocopherol and bilirubin $5 \%$.

Uric acid is water soluble and a weak serum antioxidant. The rise in uric acid in preeclampsia is not merely a nonspecific reflection of kidney damage, but a sign of antioxidative response, possibly related to the pathogenesis of Preeclampsia. 
Consistent with our study conducted by Martin Hermawan et al that showed the total antioxidant capacity measured by FRAP method was significantly higher in mild and severe preeclampsia cases than in normal pregnancy. ${ }^{15}$

In a study conducted by Zusterzeel et al, total antioxidant levels measured by FRAP assay were significantly lower in severe preeclampsia than in normal pregnancy. They used placental and decidual tissue as specimen. However, in our study, we used serum as testing material. ${ }^{16}$

A study conducted by Serdar et al proved that placental and decidual tissue was a source of lipid peroxidation that played an important role in pathophysiology of preeclampsia. ${ }^{17}$ This explains the decreased total antioxidant levels in preeclamptic patients included in the study conducted by Zusterzeel. ${ }^{16}$

In a study conducted by Kharb Simmi et al, TAC was higher in normal pregnant woman as compared to non-pregnant woman, but the increase was not significant. This can be because of higher serum uric acid level in pregnant group in third trimester, which is consistent with our study. ${ }^{18}$

In a study conducted by Maarten T.M. Raijmakers et al, patients with history of severe preeclampsia showed a significant higher antioxidant capacity as measured by the FRAP assay compared with control woman. They also concluded that the higher antioxidant capacity may be an adaptive mechanism to prevent oxidative damage. 19

\section{CONCLUSION}

There is a very strong positive correlation between MDA as well as total antioxidant capacity measured by FRAP assay with severity of preeclampsia.

Increase in the level of markers of oxidative stress in maternal circulation points strongly that oxidative stress is involved in the aetiopathogenesis of preeclampsia and supplemental dietary antioxidants may have beneficial role in the prevention of preeclampsia in women at high risk for this condition

\section{REFERENCES}

1. Kashinakunti SV, Sunitha HK, Gurupadappa, et al. Lipid peroxidation and antioxidant status in preeclampsia. Al Ameen J Med Sci 2010;3(1):38-41.

2. Hubel CA, Roberts JM, Taylor RN, et al. Lipid peroxidation in pregnancy: new perspectives on preeclampsia. Am J Obstet Gynaecol 1989;161(4):1025-1034.

3. Roberts JM, Taylor RN, Musci TJ, et al. Preeclampisa: an mendothelial cell disorder. Am J Obst Gyno 1989;161(5):1200-1204.

4. Chamy VM, Lepe J, Catalan A, et al. Oxidative stress is closely related to clinical severity of pre-eclampsia. Biol Res 2006;39(2):229-236.

5. Saxena S, Srivastava PC, Thimmaraju KV, et al. Study of serum malondialdehyde and uric acid in pregnancy induced hypertension \& its medico-legal significance. Indian Acad Forensic Med 2014;36(1):55-60.
6. Marbut MM, Majeed BM, Rahim SM, et al. Estimation of malondialdehyde as oxidative factor \& glutathione as early detectors of hypertensive pregnant women. Tikrit Medical Journal 2009;15(2):63-69.

7. Bhuyar BK, Shamsuddin M. Study of serum malondialdehyde level in pre-eclampsia. Int J Biol Med Res 2014;5(3):4159-4162.

8. Benzie IF, Strain JJ. The ferric reducing ability of plasma (FRAP) as a measure of antioxidant power: The FRAP assay. Analytical biochemistry 1996;239(1):70-76.

9. Alexa ID, Jerca L. The role of oxidative stress in the aetiology of preeclampsia. Rev Med Chir Soc Med Nat Lasi 1996;100(1-2):131-135.

10. Halliwell B, Chirico S. Lipid peroxidation: its mechanism measurement and significance. Am J Clin Nutr 1993;57(suppl 5):715S-724S.

11. Gohil JT, Patel PK, Priyanka G. Evaluation of oxidative stress and antioxidant defence in subjects of preeclampsia. J Obstetrics \& Gynaecology 2011;61(6):638640.

12. Dave J, Vaidya M, Varma M. A comparative study of degree of oxidative stress in pre-eclamptic \& healthy pregnant women in MP, India. International Journal of analytical pharmaceutical and biomedical sciences 2012;1(3):397-401.

13. Sadanand PB, Mallikarjun KV, Sheela KM, et al. Lipid peroxidation and non-enzymatic antioxidants status in preeclamptic and postpartum preeclamptic women. Indian Journal of Clinical Biochemistry 2008;23(1):4548.

14. Sahu S, Abraham R, Vedavalli R, et al. Study of lipid profile: lipid peroxidation and vit $\mathrm{E}$ in pregnancy induced hypertension. Indian Journal Physiol Pharmacol 2009;53(4):365-369.

15. Hermawan M, Mose JC, Madjid TH. Correlation of total antioxidant capacity measured by ferric reducing ability of plasma (FRAP) assay with the severity of preeclampsia. Indones J Obstet Gynaecol 2011;35(4):155-160.

16. Zusterzeel PL, Rutten H, Roelofs HM, et al. Protein carbonyls in decidua and placenta of pre-eclamptic women as markers for oxidative stress. Placenta 2001;22(2-3):213-219.

17. Serdar Z, Gur E, Develioglu O, et al. Placental and decidual lipid peroxidation and antioxidant defenses in preeclampsia: lipid peroxidation in preeclampsia pathophysiology 2002;9(1):21-5.

18. Kharb S, Veena $S$. Total free radical trapping antioxidant potential in normal pregnancy. J Obstet Gynaecol Ind 2004;54(3):249-50.

19. Raijmakersa MTM, Roesb EM, Zusterzeelb PLM, et al. Thiol status and antioxidant capacity in women with a history of severe preeclampsia. International Journal of Obstetrics and Gynaecology 2004;111(3):207-312. 